\title{
Reflections on the 2017 Rio AILA (Applied Linguistic) Conference through an Antipodean Lens: Practical Implications for Advisors
}

\author{
Moira Hobbs ${ }^{1}$ and Kerstin Dofs ${ }^{2}$ \\ 1. Unitec Institute of Technology, Auckland, New Zealand \\ 2. Ara Institute of Canterbury, New Zealand
}

\begin{abstract}
This article offers feedback and subsequent reflection on the week long Association Internationale de Linguistique Appliquée (AILA) Congress 2017 held in Rio de Janiero, Brazil, 23-27 July, and, in particular, on the full day international symposium involving presentations from leading researchers into learner autonomy and self-access, curated by the authors. As the co-convenors of the Research Network on Learner Autonomy (ReNLA) the authors organised this event for approximately 500 members from all around the world, along with the triennial AGM. This symposium was set within the academic and social context of at least 1500 linguists from about 60 different countries (including Scandinavia, South and North America, Asia, and the Pacific). Due to the wide range of countries represented, the variety of learning levels (primary, secondary and tertiary), and the different socio-economic backgrounds shared, there were many different narratives from teachers, researchers and advisors to learn from. As with most conferences, another valuable aspect of gathering experts together in one place, was the invaluable opportunities for networking, through both at formal and informal occasions during the five days of the congress, as well as observing the complexities of linguistic autonomy in action. This paper will be of interest to learning advisors at tertiary institutions, many of whom, although working with students in mainstream classes, also deal with language-based issues. At the end of the paper there is a list of practical implications for advisors.
\end{abstract}

\section{Background}

The following reflective article is set within the scope of both an academic and a practitioner-focused congress, where many well-known experts in the fields of 
linguistics, self-access and language and learning advising (i.e. supporting students with all aspects of study skills and academic literacy) gathered to share their ideas and thinking around learner support at all levels of education. Leni Dam from the University of Warwick, UK, an authority on learner autonomy for young students, stressed "the importance of reflection permeating not only language classrooms in general, but classrooms where learner autonomy is being developed" (2011, p.1), and at the congress she discussed advisor input using reflective portfolios with primary language learners. In the ReNLA symposium, Ana Salvi (2017), also from Warwick, extended reflective portfolios to encompass adult language learners who used graphics effectively to express themselves and their thoughts about learning to an advisor. The authors were inspired to write this reflection paper after hearing Diego Mideros (University of the West Indies), whose presentation (2017) showed how research on individuals' lived experiences can shed light on our understanding of agency and autonomy. Maria Giovanna Tassinari from Berlin reinforced the importance of communities of practice $(\mathrm{CoP})$ for both learners and advisors to encourage autonomy in self-access centres. In an earlier work, she stated that

A self-access centre should be a space for exchange and experimentation in which all actors of the learning community (teachers, learners, student assistants, tutors) have a voice and scope of action, and can innovate and evolve both personally and professionally. (2017a, p. 166).

In this way, a CoP can "create a community of actors in the educational environment Encourage exchanges and dialogue, acknowledge individual and collective resources, and create and maintain spaces of dialogue among the different actors." (p. 167). Tassinari's Rio presentation reiterated the benefits of a CoP in terms of the positive opportunities for co-research between advisors and learners (Tassinari, 2017b). Marina Mozzon-McPherson, from the University of Hull, whose previous work (2016) argued for advisors in tertiary self-access centres to form a professional body, presented on reflective practice using dialogues based on neuro-linguistic programming (NLP). She illustrated how knowledge of NLP offers useful frameworks for working with students, including a How rather than a Why approach; Feedback rather than focusing on Failure; looking at Possibilities instead of Constraints; and Following Curiosity and Fascination in preference to Making Assumptions (2017).

Hobbs, M., \& Dofs, K. (2017). Reflections on the 2017 Rio AILA (Applied Linguistic) conference through an Antipodean lens: Practical implications for advisors. ATLAANZ Journal 2(2): 48-63. 
The main aim of self-access centres is to foster autonomy, and Mynard and Carson (2012) outlined a framework, which describes the relationships between advising, language learning, and learner autonomy, advocating for advising be regarded as a distinct profession developing its own collection of practices and discourses. Hayo Reinders (Unitec, NZ) and Cynthia White (Massey, NZ) put forward thoughts about the future of learner autonomy (2017), and discussed the thrust of today's technology and the possibilities for advisors to use this technology to give useful feedback to learners in the future: "... we see that individuals draw on their identities and agency in creating technology-mediated language spaces for themselves, and it is out of these processes and activities that affordances arise for language learning in their everyday lives." (p. 177). ${ }^{1}$ Terry Lamb collaborated with Goran Vodicka (both from University of Sheffield, UK) to show the value of engaging language learners with existing linguistic landscapes, such as road signs, building signage, posters, shop frontages and public information boards etc. (forthcoming) and suggested ways advisors could encourage students to embrace this potential input.

While thinking about the presentations mentioned above, the authors of this paper are putting into practice part of McKay's model of Foundations of Reflective Practice (2017): combining classroom experience, general knowledge and personal values. Advisors can reflect 'in' action as well as 'on' action. As Westberg and Jason (2001) explained, 'in' action requires reflection on two levels: (1) as and when you are involved with the learner, e.g. eliciting information, observing, questioning and assessing potentially useful assistance; and (2) as you continuously adapt your level of assistance. Then you reflect 'on' action, i.e. remain reflective and note any surprises, troubling events, or unanswered questions. Reflecting in this way will enable ongoing learning from experience, and can provide high quality support to students.

Reflective practice has been researched and implemented for some time (Hébert, 2015; Jones \& Jones, 2013; Kolb \& Kolb, 2005; Lane, McMaster, Adnum \& Cavanagh, 2014; Larrivee, 2000; Leitch \& Day, 2000; Ontario Ministry of Education, 2007; Segon and Booth, 2012). Nevertheless, Kato and Mynard (2015) provided a good introduction to the background and skills necessary for advisors to engage in effective reflective

\footnotetext{
${ }^{1}$ For example, when visiting Indonesia recently, one of the authors of this paper noted that seemingly impoverished pupils of rural schools all appeared to have smart phones, which could be used for language learning in their home environments.
}

Hobbs, M., \& Dofs, K. (2017). Reflections on the 2017 Rio AILA (Applied Linguistic) conference through an Antipodean lens: Practical implications for advisors. ATLAANZ Journal 2(2): 48-63. 
dialogue with learners, such as knowledge in the areas of reflective practice, sociocultural theories, autonomous learning and advising, as well as aspects of counselling and life coaching. While the following paper is a descriptive, reflective piece incorporating the writers' personal actions and responses to various aspects of the conference, it aims to offer some pointers to people currently involved in advising in their own institution.

\section{The context of the authors' reflections}

Standing at the hotel window in Rio de Janiero, we felt a little like being under exotic house-arrest with army helicopters overhead and armed soldiers in the street. It is pertinent to note that these feelings of constraint, which also formed part of the "lived experience' during the Congress (linguistically, culturally and politically), were in fact merely the authors' personal representations of Brazil's much wider endemic sociopolitico-cultural context since at least 1888 when slaves were freed and had to make do with favela trees to build housing in their newly-emancipated lives. Nowadays, these 'favela' neighbourhoods account for about 3 million of the approximately 8 million population of Rio. They feature on all but one or two hillsides, are often dominated and ruled by drug lords and associated gangs, and residents suffer from negative societal effects of drug use.

Normally, the images associated with Rio are beautiful surf beaches such as Ipanema and Copacabana, the Christ the Redeemer statue, and Sugar Loaf Mountain. While these features are still there, unfortunately the visual landscape round the congress also included armed guards, camouflaged vehicles and newspaper articles about a spike in crime and political unrest. Indeed, as the authors had never previously experienced this level of political engagement at a conference, it was rather surprising that the first AILA keynote, and another highly-regarded presenter at the Research Network Learner Autonomy (ReNLA) symposium day, took time at the beginning of their presentations to deliver a form of short political broadcast seeking solidarity as they gave voice to their concerns about the government and President of the day, after which they received rounds of applause from other attendees.

Still today, the gaps in Brazil between rich and poor, between the government and the governed, between the lifestyles of those holding most of the power and those 
with little, are dramatic. This impression came through subsequent comments from several Brazilian academics, as well as presentations by other scholars researching 'the South'. As alluded to above, politics (and corruption) held left, right and centre stage, with calls for unity and support in opposition to government management and blatant, flagrant misuse of public funds and budgets, particularly with respect to education and other essential social services. The current situation in Rio had also contributed to a palpable sense of social and political unrest, and the government's need to import 10,000 troops, both police and army, in an attempt to halt the escalating crime wave. This was partly fuelled by the impeachment of the previous Prime Minister and a feeling of the pending 'dispatch' of the current PM, set within the wider context of South America, where Venezuela was also undergoing controversial elections that Colombia had already stated would not be recognised. These sobering discourses certainly served to put into perspective the challenges experienced by other more fortunate countries at the institutional, pedagogical, classroom delivery and financial levels, and reinforced appreciation of the relatively stable political and economic context here in Australasia.

In spite of this surrounding climate, all the educators who gathered at the congress were driven to maintain learning support services for those learners privileged to have the opportunity for education, even though some teachers were acting with no institutional support and few resources, and others had to fund student support from their own pockets, using any rooms or materials they could find. On the other hand, there was also one powerful and privileged delegate who maintained and reinforced the status of the elite, lavishly using resources at the congress, rather than being more economical, which might have enabled more people from the same institution to attend. At the same time, this delegate was decrying the government's corrupt economic practices that resulted in mis-spending funding essential for the poorest and least educated in the community.

Now, having set the scene by reflecting on the incongruities of the local situation, this paper will move on to a discussion of the actual content and experience of the congress.

Hobbs, M., \& Dofs, K. (2017). Reflections on the 2017 Rio AILA (Applied Linguistic) conference through an Antipodean lens: Practical implications for advisors. ATLAANZ Journal 2(2): 48-63. 


\section{The AILA congress and the ReNLA symposium}

It was wonderful to be able to meet, hear and network with so many colleagues also working in a similar field, and it was delightful to find a good representation of fellow New Zealanders, eight from Auckland and two from Christchurch. While the main congress theme was 'Innovation and Epistemological challenges in Applied Linguistics', the authors' main task was to facilitate a research symposium for the ReNLA, including giving an overview of the autonomous learning and self-access contexts in our respective institutions, which is directly relevant to learning advisors. The presentations at the symposium by language learning centre experts and academics from around the world followed the main theme, "Learner autonomy in today's developed and developing world", and were grouped into four sub-themes:

(i) Delineations and meanings of space and place for autonomy

(ii) Assessing the presence, extent and benefits of autonomy

(iii) Exposition of innovative educational practices as they impact on autonomy

(iv) South American autonomy aspects to research and practice The content of presentations was wide ranging, from a variety of different perspectives and situations - from teachers to learners and advisors, from wealthy to extremely poor countries, from individual to group autonomy, and from interview-based research to output-based discussion of autonomy using digital platforms (see Figure 1.):

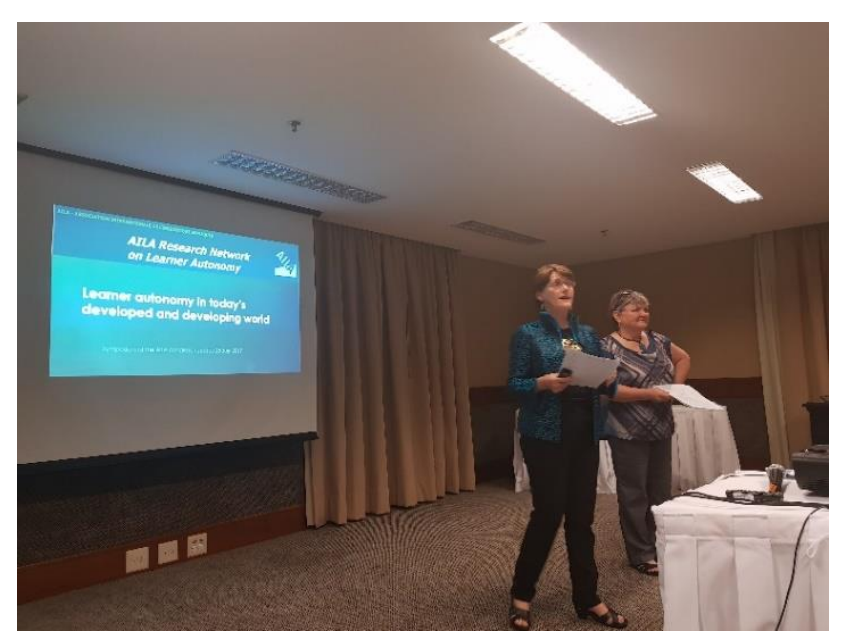

Figure 1. The authors introducing the symposium

Hobbs, M., \& Dofs, K. (2017). Reflections on the 2017 Rio AILA (Applied Linguistic) conference through an Antipodean lens: Practical implications for advisors. ATLAANZ Journal 2(2): 48-63. 
Speakers discussed how both agency and autonomy are important for second-language (L2) learning, and that autonomy is not the same as working alone. Some delegates focused on learners' social autonomy while others talked about the implications for research. Some stressed the importance of allowing space and place for autonomy in institutional developments, and why specific curriculum changes may be successful or unsuccessful. There was focused discussion around virtual spaces such as Moodle and Second Life, as well as the need for real-world spaces to enable students to reflect on their own learning. Other presentations covered innovative educational practices such as peer collaboration, and the use of information and communication technologies (ICT). Attendees also heard about the South American approaches to research and practice within the autonomous learning field, which highlight aspects of equality.

It is clear that many educational institutions around the world continue to support autonomous learning even if learning contexts are changing, particularly with the growing use of digital technology. Many institutions are gradually moving towards an 'anytime, anywhere, any device' (Wisembly, 2015) philosophy, which may actually require learners to be even more adept at managing their own time and taking responsibility for their own learning, to study efficiently, and to be successful - that is, to be autonomous. Advisors need to understand this in order to enable their learners, and institutions need to provide space and place, facilities and resources for autonomous learning to take place.

As previously mentioned, the authors' main role as convenors was to manage the ReNLA research symposium day and give an overview of the autonomous learning and self-access contexts at their institutions in New Zealand. The third ReNLA convenor from Australia could not attend, so this offered the opportunity to put a real kiwi stamp on the day. This started with a kinaesthetic cultural component where the authors invited everyone to write their pepeha or personal greeting ("Pepeha what is it?", n.d.) so they could introduce themselves in Māori (see Figure 2). 


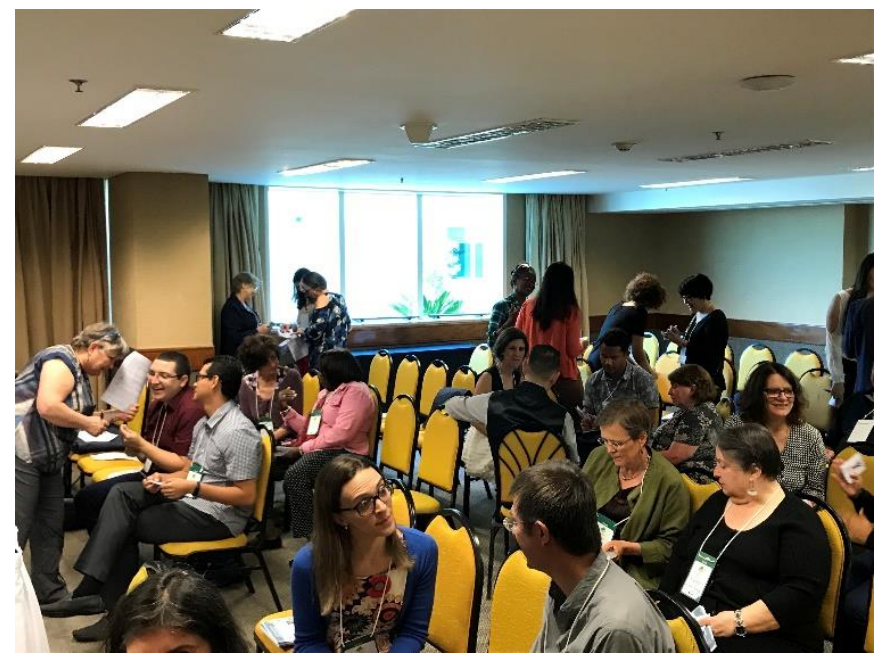

Figure 2. Symposium attendees engaged in the pepeha

The welcome session incorporated the concept of waiata (song), in this case 'Tutira mai nga iwi', to begin and end the day's 'autonomous learning' journey (see Figure 3). We explained the history of the song's creation and the lyrics sheet also included an English translation and information about the reasons for singing waiata.

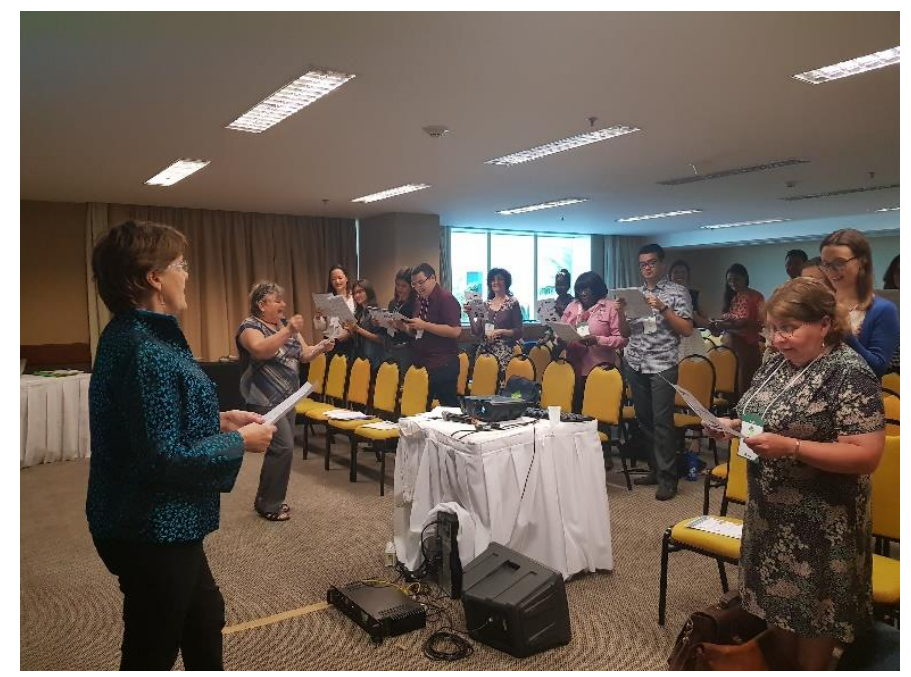

Figure 3. Everyone enjoying the waiata

Hobbs, M., \& Dofs, K. (2017). Reflections on the 2017 Rio AILA (Applied Linguistic) conference through an Antipodean lens: Practical implications for advisors. ATLAANZ Journal 2(2): 48-63. 
Alongside these bicultural elements, the authors provided local treats to keep the blood sugar levels from flagging. Interactive discussions followed each block of 3-4 presentations, incorporating shared question times for the panel of presenters. During the course of the day, energy levels and sustenance were supported and encouraged by a selection of kiwi favourite sweets handed around at appropriate times - a selection of marshmallow chocolate fish, Minties, pineapple lumps and jaffas (see Figure 4) - all greatly appreciated. (Delegates gave a round of applause after the surprise of the initial round.)

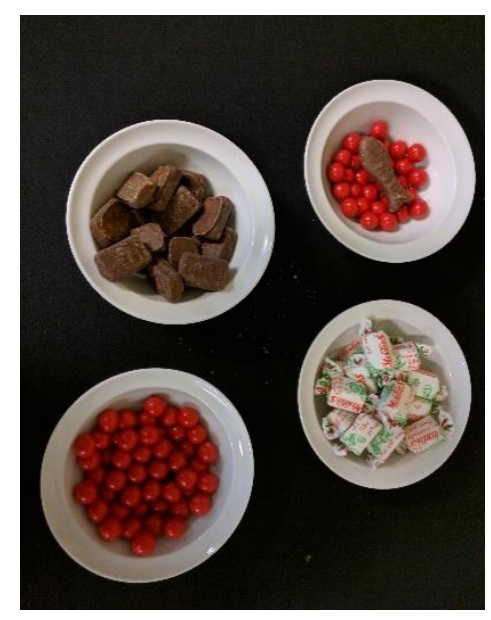

Figure 4. Kiwi sweets

Then, at the end of the day, the authors brought all presenters to the front of the room to honour and thank them for their hard work researching and preparing their papers for the symposium, and gave each a koha token of acknowledgement in the form of a handmade recycled rimu soap dish, accompanied by hand-made kawakawa soap (see Figure 5), which both amazed and thrilled the recipients.

Hobbs, M., \& Dofs, K. (2017). Reflections on the 2017 Rio AILA (Applied Linguistic) conference through an Antipodean lens: Practical implications for advisors. ATLAANZ Journal 2(2): 48-63. 


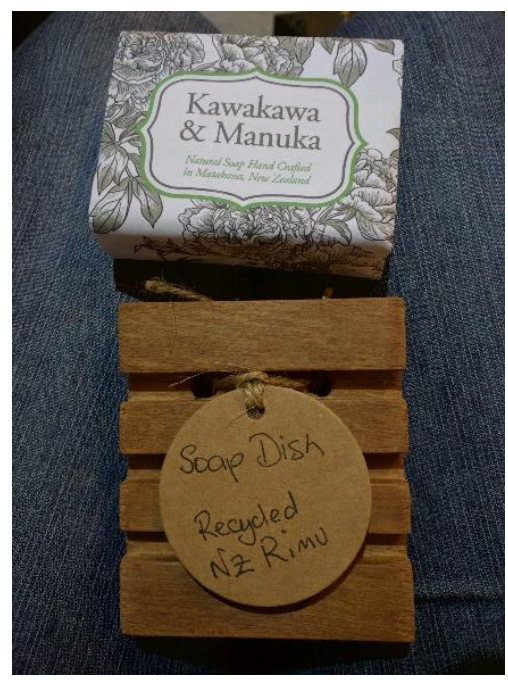

Figure 5. New Zealand gifts for symposium presenters

Everyone seemed delighted to welcome this inclusion of mātauranga Māori - Māori knowledge, wisdom, understanding, skill (Mātauranga, 2011). This also contributed to the extra dimension of whanaungatanga, the relationship developed through shared experiences and working together that provides people with a sense of belonging (Whanaungatanga, 2011), so much so that, when the waiata was repeated to close the day, everyone was so engaged that they requested to sing it a second time. Then later, as everyone was celebrating the success of the day over drinks at a balcony bar nearby, one of the attendees found the song on Youtube, which he played on his phone and everyone sang along again - a great example of an emerging community of practice and group autonomy.

During the introduction, the authors outlined the changing face of space and place in their institutions, followed up with a final presentation describing what this means in their own tertiary settings, where transformations and rebuilding are taking place at each institution. The developments were discussed in light of increased digitisation of teaching and learning and increasing institutional requirements for, and dependence on, blended learning. A common theme of both authors' institutions is the increasing focus on online, digital and collaborative modes of learning, mainly via BYO devices, with on-campus lectures delivered in multi-purpose. Such developments highlight that advising practices also need to develop alongside the physical and virtual modes of teaching and learning, as do the underpinning pedagogies within Language Learning Centres - and indeed whole institutions - within the New Zealand version of the developed world. 
At one point of the symposium day, the authors had the pleasure of introducing one of the most long-standing members of the autonomous learning community, Terry Lamb (see Figure 6), who informed ReNLA delegates about the impending output from the previous AILA congress 2014, a work he is co-editing with Garold Murray (equally well-known in the discipline) from the University of Okayama. Their book, Space, Place and Autonomy in Learning and Teaching is in its final stages of publication by Routledge, with a proposed launch date of early 2018.

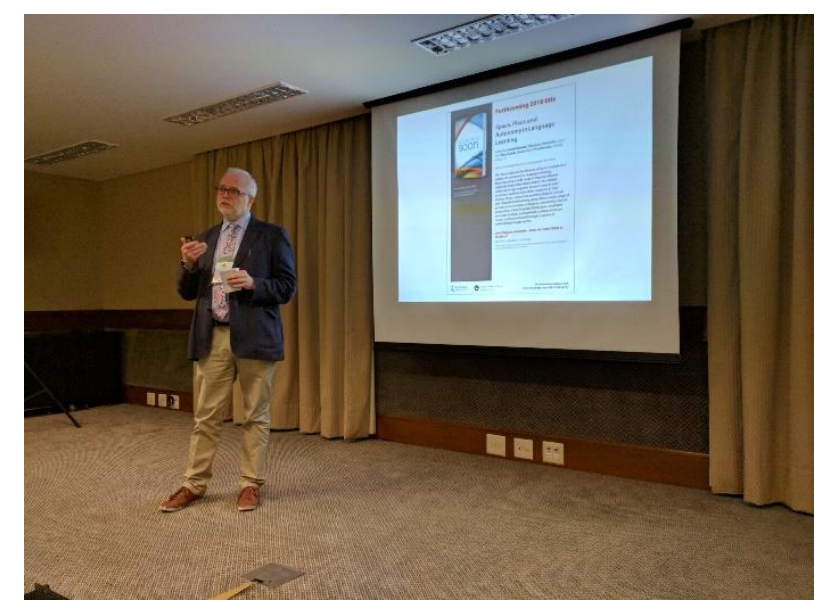

Figure 6. Lamb introducing his forthcoming book.

We have already highlighted the importance of considering spaces and places in order for learners to feel at home and encouraged in the autonomous learning components of their courses (Dofs \& Hobbs, 2011) and have also contributed to Lamb and Murray's book. Our chapter, entitled "Spaced out or Zoned In? An exploratory study of spaces enabling autonomous learning in two New Zealand tertiary learning institutions" (Hobbs \& Dof, forthcoming), explores the physical, imagined, virtual, and social learning spaces at our two institutions, including the linguistic landscape within the language learning centres. It describes students claiming desired places for learning, embodying them and imposing their identities on them. It also outlines the importance of such learning spaces for encouraging a sense of belonging and autonomous development amongst students. The day concluded with a celebration of the successes of members of the ReNLA community, including several PhD completions and near completions, and a host of publications in various journals and books penned by members.

Hobbs, M., \& Dofs, K. (2017). Reflections on the 2017 Rio AILA (Applied Linguistic) conference through an Antipodean lens: Practical implications for advisors. ATLAANZ Journal 2(2): 48-63. 


\section{Authors' reflections on symposium and congress}

From an academic and personal perspective, the symposium was a very successful day, with contributors from Japan, the UK, NZ, Brazil, Germany and Austria. Overall, the ReNLA symposium contained some surprises, examples of teachers fighting for their students' autonomy and learning capability, new areas of potential enquiry, and much food for thought. There were many very interesting keynotes and presentations over the five-day conference. Generally, the whole AILA Congress 2017 was a very worthwhile conference, despite a few linguistic, cultural and political restraints. Other concepts that presenters talked about at the congress were: multimodal discourses and semiotics of place; group autonomy; lived experience as a concept used by researchers to describe and analyse participants' narratives; one's positionality as a researcher; and the role of learner advising.

On reflection, using the combination of classroom experience, general knowledge and personal values as described above (McKay, 2017), we noted certain aspects that seemed to recur within the AILA congress:

- Some delegates perhaps felt 'othered' when two other New Zealanders spoke in Māori at the breakfast table when clearly others in the group did not understand. even though one of the other non-Māori diners explained the terminology 'whanau' (support person) to a Finn also having breakfast. On the one hand, this could be interpreted as an example of autonomy, with the Te Reo speaker reinstating and taking back the power of the indigenous language of New Zealand. Of course, it could simply have been that the Maori speakers had something private to talk about, although etiquette would suggest it is rude to do this.

- One example of not allowing autonomy to blossom was when an Englishspeaking delegate felt 'othered' when trying to communicate in the local Portuguese language, and the Portuguese speaker replied in English. Even though the responder may have simply been trying to ensure the clarity of the communication, it seemed that the attempt at assimilating was being overridden, which in turn also served to dismiss the initiator's attempt at autonomy and feelings of self-efficacy. 
- Nevertheless, on other occasions, different local speakers were keen to give corrective feedback and take time to explain local pronunciation. These gestures made visitors feel more welcome and that their attempts at communication in the host language were being appreciated and supported.

- With such a multilingual group of individuals, conversations were continually being 'checked', vocabulary queries 'accepted' and discourses 'repaired'. This reinforces the importance of advisors being aware of their students' learning experiences, and promoting such communication strategies during advising sessions.

- There were three official languages at the congress - Spanish, Portuguese and English, and the keynotes were usually delivered in English, with slides translated in the other language/s. However, even in the multicultural hotel eating area, there were two examples of 'othering' and 'marginalisation' of English: a series of large, framed cartoons with captions only in Portuguese, thus excluding most tourists to the hotel (perhaps because English language is no longer automatically a part of the Brazilian school curriculum). Similarly, it was noted that there were no English language newspapers, only Spanish and Portuguese, in the hotel lobby and general concourse area.

- It could be argued that delegates speaking te reo in an international arena, locals correcting non-native speakers and the decision to make English optional in the Brazilian school curriculum are all examples of autonomy in action.

Nevertheless, the resultant sense of being 'othered' in these instances highlights the complexities of language and communication practices.

\section{Conclusion and implications for advising}

Overall, the main implications derived from the practitioner research and reflective practice encountered in the presentations we attended at the AILA Congress and ReNLA symposium, which focused mainly on linguistics, language and learning advising, learner autonomy and self-access, bring to light several key notions, which could be useful for both language and learning advisors: 
- being aware that linguistic expressions and academic language which advisors use with students used during individual advising sessions, need to reflect the culture and the language level of the students they are working with;

- acknowledging and respecting each different student's cultural background, and being inclusive within the advising session;

- the importance of not othering others: meeting students 'where they are' so as not to make them feel marginalised, showing respect at all times whatever their language level, general learning level and cultural/religious backgrounds;

- the need to use language everyone can understand when working with a group of students from several countries;

- the usefulness of utilising communication strategies of checking, repairing and accepting;

- the value of advisors engaging in communities of practice (see Tassinari, 2017);

- making use of the framework outlined by Mynard and Carson (2012) to develop relationships between advising, language learning, and learner autonomy;

- using NLP techniques (see Mozzon-McPherson, 2017)when undertaking reflective dialogues with learners ;

- understanding how emerging technologies can encourage learner efficacy (see Reinders \& White, 2017), in order to generate more useful and effective feedback from advisors.

Thoughts are already forming around possible themes and different New Zealand cultural input that can be incorporated into the ReNLA symposium for the next congress, which has the theme "The dynamics of language, communication and culture in a changing world", and will be held 9-14 August 2020, at the University of Groningen in the Netherlands. We hope that our colleagues and advisors at other institutions around Australasia have also been able to gain some new insights and ideas from our reflections and discussion above, can try to incorporate these into their practice, and can join us in the Netherlands. 


\section{References}

Dam, L., \& Legenhausen, L. (2011). Explicit reflection, evaluation, and assessment in the autonomy classroom. Innovation in Language Learning and Teaching, (5)2, 177-189.

Dofs, K., \& Hobbs, M. (2011). Guidelines for maximising student use of independent learning centres: Support for ESOL learners. Christchurch, New Zealand: Ako Aotearoa Southern Hub. Retrieved from https://akoaotearoa.ac.nz/download/ng/ file/group-7/guidelines-for-maximising-student-use-of-independent-learningcentres.pdf

Hébert, C. (2015). Knowing and/or experiencing: a critical examination of the reflective models of John Dewey and Donald Schön. Reflective Practice: International and Multidisciplinary Perspectives, 16(3), 361-371. doi 10.1080/14623943.2015.1023281

Hobbs, M., \& Dofs, K. (forthcoming). Spaced out or zoned in? In G. Murray, \& T. Lamb. (Eds.), Space, place and autonomy in language learning. London, UK: Routledge.

Jones, J., \& Jones, K. (2013). Teaching reflective practice: Implementation in the teacher-education setting. The Teacher Educator, 48(1), 73-85. doi 10.1080/08878730.2012.740153

Kato, S., \& Mynard, J. (2015). (Eds.). Reflective dialogue: Advising in language learning. New York, NY: Routledge.

Kolb, A., \& Kolb, D. (2005). Learning styles and learning spaces: Enhancing experiential learning in higher education. Academy of Management Learning and Education, 4(2), 193-212. doi 10.5465/AMLE.2005.17268566

Lamb, T., \& Vodicka, G. (forthcoming). Collective autonomy and multilingual spaces in super-diverse urban contexts: Interdisciplinary perspectives. In G. Murray, \& T. Lamb (Eds.), Space, place and autonomy in language learning. Abingdon, UK: Routledge.

Lane, R., McMaster, H., Adnum J., \& Cavanagh, M. (2014). Quality reflective practice in teacher education: A journey towards shared understanding. Reflective Practice: International and Multidisciplinary Perspectives, 15(4), 481-494. doi 10.1080/14623943.2014.900022

Larrivee, B. (2000). Transforming teaching practice: Becoming the critically reflective teacher_Reflective Practice: International and Multidisciplinary Perspectives, 1(3) 293-307. doi 10.1080/713693162

Leitch, R., \& Day, C. (2000). Action research and reflective practice: towards a holistic view. Educational Action Research, 8(1), 179-193. doi 10.1080/09650790000200108

Hobbs, M., \& Dofs, K. (2017). Reflections on the 2017 Rio AILA (Applied Linguistic) conference through an Antipodean lens: Practical implications for advisors. ATLAANZ Journal 2(2): 48-63. 
Mātauranga. (2011). Te aka Māori-English, English-Māori dictionary. Retrieved from http://maoridictionary.co.nz/search?idiom $=\&$ phrase=\&proverb=\&loan=\&keywo rds=matauranga\&search $=$

McKay, S. (2007). Characteristics of reflective teaching. Retrieved from http://learnexperienceteach.com/2015/11/08/characteristics-benefits-ofreflective-teaching/

Mideros, D. (2017, July). Phenomenologies of autonomy and agency in the South Caribbean: The case of Trinidad and Tobago. Paper presented at the AILA Congress Rio, Brazil.

Mozzon-McPherson, M. (2016). Language advising at the University of Leeds. [Video interview]. Retrieved from https://www.youtube.com/watch?v=5t1wlF1HXqo

Mozzon-McPherson, M. (2017). Reflective dialogues in advising for language learning: neuro-linguistic programming perspective. In C. Nicolaides, \& W. Magno (Eds.), Innovations and challenges in applied linguistics and learner autonomy (pp. 209-229). Rio de Janeiro, Brazil: Pontes Editores.

Mynard, J. \& Carson, L. (2012). (Eds.). Advising in language learning: Dialogue, tools and context. New York, NY: Routledge.

Ontario Ministry of Education. (2007). Capacity building series: Student selfassessment, Literacy and Numeracy Secretariat capacity building series. Ontario, Canada: Queens Printer.

Pepeha: What is it? (n.d). Retrieved from http://www.maori.org.nz/tikanga/default.php?pid=sp72\&parent=71

Reinders, K., \& White, C. (2017). Re-imagining the margins: Exploring the transformation potential of technology and out-of-class learning. In C. Nicolaides, \& W. Magno (Eds.), Innovations and challenges in applied linguistics and learner autonomy (pp.167-182). Rio de Janeiro, Brazil: Pontes Editores.

Salvi, A. I. (2017, July). The synergies between a pedagogy for autonomy and criticality development in EAP in HE in the UK. Paper presented at the AILA Congress Rio, Brazil.

Segon, M. \& Booth, C. (2012). The connection of reflective practice to management competency through a business simulation. Research and Development in Higher Education: Connections in Higher Education, 35, 271-281. Hobart, Australia: HERDSA.

Hobbs, M., \& Dofs, K. (2017). Reflections on the 2017 Rio AILA (Applied Linguistic) conference through an Antipodean lens: Practical implications for advisors. ATLAANZ Journal 2(2): 48-63. 
Tassinari, M. G. (2017a). Encouraging autonomy through a community of practice: The role of a self-access centre. Studies in Self-Access Learning Journal, 8(2), 157168.

Tassinari, M. G. (2017b, July). Co-research in practice in a self-access language centre. Paper presented at the AILA Congress Rio, Brazil.

Westberg, J., \& Jason, H. (2001). Fostering reflection and providing feedback: Helping others learn from experience. New York, NY: Springer Publishing Company.

Whanaungatanga. (2011). Te aka Māori-English, English-Māori dictionary. Retrieved from http://maoridictionary.co.nz/word/10068

Wisembly. (2015, October 15). Anytime, anywhere, any device: The ATAWAD concept Retrieved from https://wisembly.com/en/blog/2015/10/15/anytime-anywhereany-device-the-atawad-concept 